\title{
Statistics of long-term ionospheric measurements
}

\author{
T. Damboldt ${ }^{*, * *}$ and P. Suessmann ${ }^{*, * *}$ \\ *retired \\ ** formerly at: Forschungsinstitut der Deutschen Bundespost beim FTZ Darmstadt, Darmstadt, Germany \\ Correspondence to: T. Damboldt (thomas.damboldt@t-online.de)
}

\begin{abstract}
It is shown that after elimination of the dominant influence of solar activity, the height hmF2 of the maximum ionisation of the ionosphere (which is inversely linearly related to $\mathrm{M}(3000) \mathrm{F} 2$ as described for example by the Shimazaki formula) shows a marked decrease during the recent solar minimum (2005 to 2009) of about $20 \mathrm{~km}$. This is in accordance with results of studies of the decreased neutral density of the lower thermosphere and the density decrease at about $400 \mathrm{~km}$ during the unusual recent solar minimum. It is also shown that there is a trend reversal in the height of the ionosphere hmF2 in about 1963/1964 with a negative trend from 1942 to 1963 and a positive trend from 1964 to 2005. This is in contrast to the results reported in most other publications of ionospheric long-term trends. There is no significant trend in foF2 and, particularly, none of the effects described above for hmF2 could be found in foF2.
\end{abstract}

\section{Introduction}

A database of about 1.5 million monthly hourly median values of each of the two ionospheric parameters foF 2 and M(3000)F2 measured worldwide between 1941 and 2009 was created recently (Damboldt and Suessmann, 2011), using data available in the World Data Centres (WDC). This large collection of measurements provides the basis for the study of long-term variations of the ionosphere, up to almost 7 solar cycles.

\section{Elimination of solar cycle induced variations}

For the derivation of trends in ionospheric properties it is advisable to remove the strong influence of the solar cycle if data is only available for a few solar cycles, which is the case here, as observations began only in 1941. The solar (and geomagnetic) influence is usually eliminated by a linear regression (e.g. Bremer, 1992). In the present paper an alternative method is applied, namely the comparison with an ionospheric model, in this case with the CCIR ionospheric prediction model (ITU, 2010). This model considers solar activity as the main parameter and as an empirical model based on ionospheric observations made in the years around the International Geophysical Year (IGY) it inherently includes also the effects of short-term variations of the Earths magnetic field. The model is based, however, on a fixed magnetic field epoch of 1960 . For foF2, the model consists of 988 coefficients for each month and two levels of solar activity, i.e. $988 \times 2 \times 12=23712$ coefficients in total. For M(3000)F2, the model consists of 441 coefficients for each month and two levels of solar activity, i.e. $441 \times 2 \times 12=10584$ coefficients in total. The ionospheric parameters foF 2 and M(3000)F2 can be calculated for any time and geographic position using these coefficients. Alternatively these parameters can be extracted easily from numerical tables (ITU, 2010). This model can be used to calculate the differences between observed and predicted foF 2 and $\mathrm{M}(3000) \mathrm{F} 2$ for each station location, each month, and each hour. From these individual differences yearly averages are calculated, and then from these values linear trends can be derived. The advantage of this method is, that all observations can be used whereas the regression method requires a certain minimum number of observations (normally two solar cycles) in order to produce a meaningful regression line. In a recent paper, Bremer et al. (2011) have shown that the two methods to eliminate the solar cycle are equivalently suitable for this purpose.

\section{Trend in the ionospheric height hmF2}

In the new database there are 1393561 monthly hourly measured $\mathrm{M}(3000) \mathrm{F} 2$ values from more than 230 stations. In the present work $\mathrm{hmF} 2$ has been used instead of $\mathrm{M}(3000) \mathrm{F} 2$, 


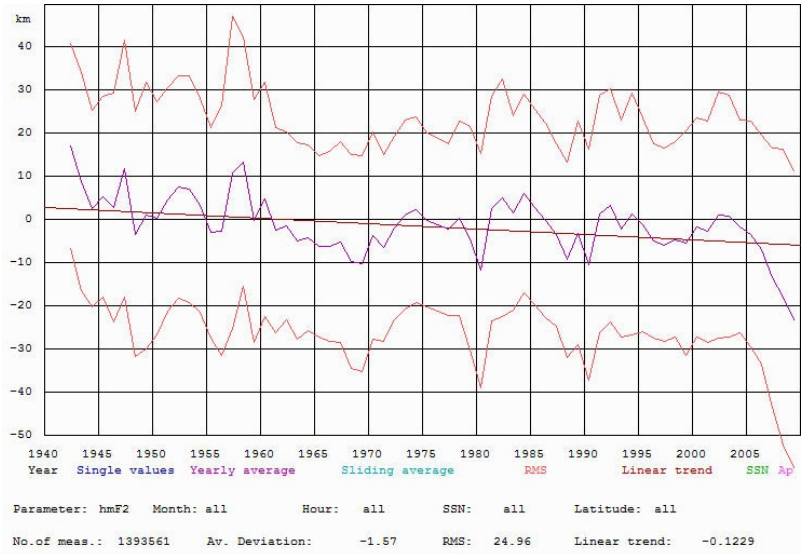

Fig. 1. Yearly average hmF2(obs)-hmF2(pred) from 1941 to 2009 and resulting trend-line.

as the height of the ionosphere in kilometres is more attractive than the M-factor. The conversion of $\mathrm{M}(3000) \mathrm{F} 2$ into $\mathrm{hmF} 2$ was achieved by applying the simple Shimazaki formula (Shimazaki, 1955).

$\mathrm{hmF} 2=1490 / \mathrm{M}(3000) \mathrm{F} 2-176$

More modern, perhaps more accurate, formulas can not be applied here as the databank used does not provide the information needed (particularly foE). Moreover Bremer (1992) has shown that the choice of the formula is not critical for the derived trends. A comparison of the measurements $\mathrm{hmF}$ 2(obs) with the values predicted $\mathrm{hmF}$ (pred) according to the CCIR method (ITU, 2010) was performed. There are about 20000 monthly values used for the calculation of each yearly average with substantially fewer values in the first 5 years. Figure 1 shows the yearly average differences $\mathrm{hmF}$ (obs) $-\mathrm{hmF} 2$ (pred) and the corresponding yearly RMS values. It can be seen that the yearly average differences are quite small, actually in the order of the accuracy of the measurements. The causes of these variations are still to be determined. The RMS is quite constant at about $\pm 25 \mathrm{~km}$. If one wishes to calculate a linear trend, this would be about $0.12 \mathrm{~km} y e a r^{-1}$ and in the following it is questioned whether that is statistically significant or not, particularly noting a trend reversal from negative to positive in about 1963/1964.

\subsection{Unusual decrease of hmF2 after 2005}

A major feature in Fig. 1 is the substantial decrease of the height of the ionosphere after 2005. This is probably due to the extremely low solar EUV emission during the solar minimum 2005 to 2009 (Solomon et al., 2010) which affected also other heights of the atmosphere (Emmert et al., 2010; Jacobi et al., 2011).

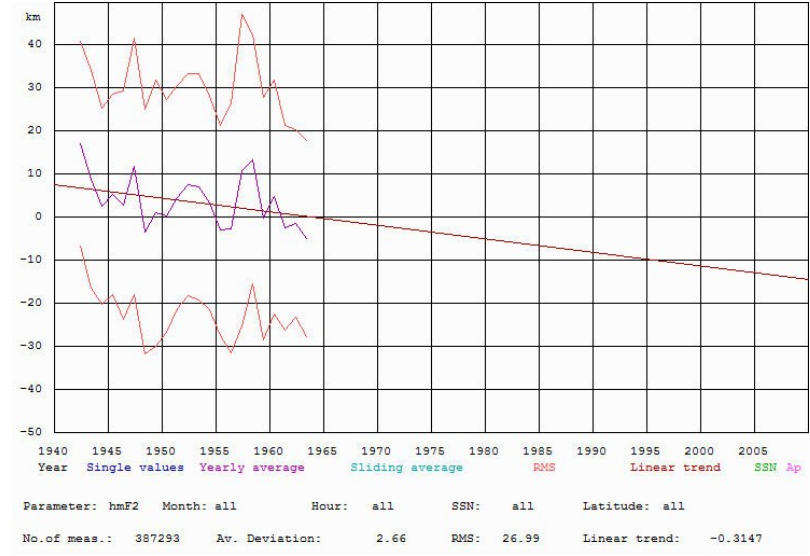

Fig. 2. Yearly average hmF2(obs) - hmF2(pred) from 1941 to 1963 and resulting trend-line.

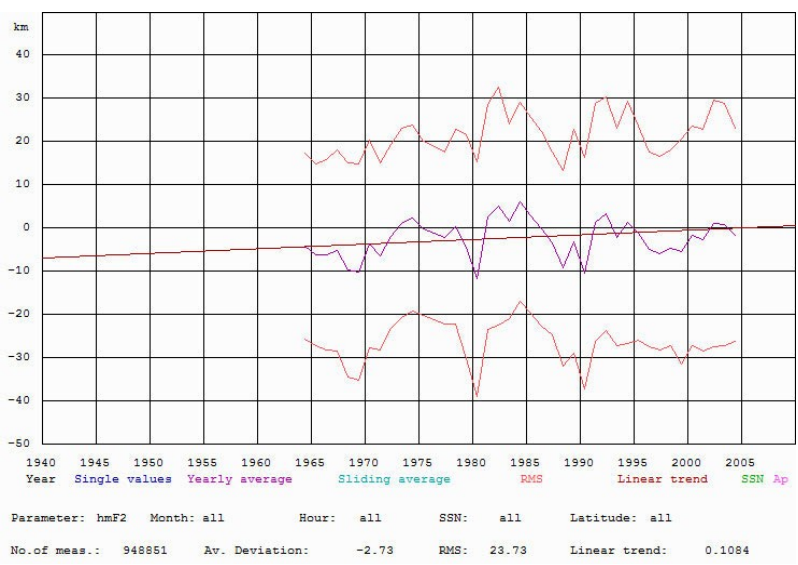

Fig. 3. Yearly average hmF2(obs) - hmF2(pred) from 1964 to 2004 and resulting trend-line.

\subsection{Unusually “quiet” period from 1962 to 1972}

Another feature in Fig. 1 is the unusually "quiet" period from 1962 to 1972 in which a very low solar maximum occurred, which may be connected with lower EUV radiation than normally associated with the corresponding sunspot number.

\subsection{Trend reversal}

The unusual behaviour during the solar minimum from about 2004 to 2009, where very low solar EUV radiation played a major role, is an indication against the calculation of a trend for the whole period from 1941 to 2010. Therefore the period under study is limited to 2004, at least for $\mathrm{hmF} 2$. Moreover, a closer look at Fig. 1 reveals a trend reversal in about 1963/1964. The trend calculated for the years 1941 to 1963 (Fig. 2) is $-0.31 \mathrm{~km} \mathrm{yr}^{-1}$, the trend calculated for the years 1964 to 2004 (Fig. 3) is $+0.10 \mathrm{~km} \mathrm{yr}^{-1}$. This is in contrast to most publications about the trend in the ionospheric height 


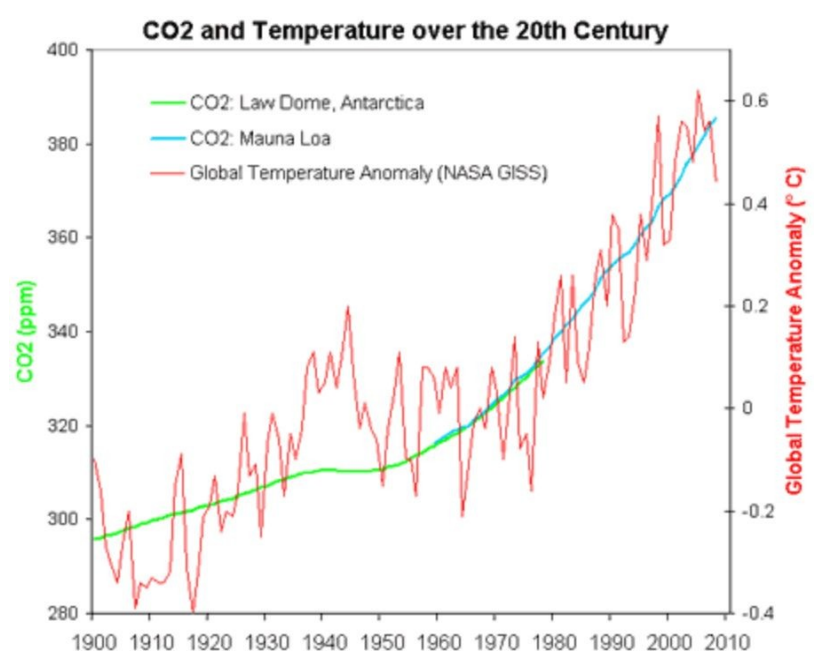

Fig. 4. Temperature and $\mathrm{CO}_{2}$-trends 1900-2004 (green and blue lines $\mathrm{CO}_{2}$ derived from Law Dome and Mauna Loa, red line temperature from GISS).

parameter hmF2 (e.g. Bremer, 1998) and is particularly in contrast to Rishbeths theory of a lowering of the ionosphere due to increased density of greenhouse gases in the atmosphere (Rishbeth, 1990; Rishbeth and Roble, 1992). The measured $\mathrm{CO}_{2}$ densities (Fig. 4) increased by about $20 \%$ from 1970 to 2010 and do not show any similarity to the trend in hmF2 (Fig. 1). According to Rishbeth's theory the height of the ionosphere should have decreased by about 2 to $4 \mathrm{~km}$ during those 40 years, but that is not the case: see Fig. 3 . Our assumption is that the long-term trend in $\mathrm{hmF} 2$ may have other important causes besides solar EUV radiation, but it seems that $\mathrm{CO}_{2}$ is not the most important one. It has been shown recently (Lühr et al., 2012) that the occurrence frequency of equatorial plasma bubbles is influenced by meteorological phenomena at low latitudes. With this knowledge and looking at Fig. 4, the trend reversal in hmF2 may have its origin in the global surface temperature trend reversal occurring in the same time frame. Looking at Fig. 5, it may be pure coincidence that the temperature in the earth's surface shows an amazing similarity with the solar 80-year solar cycle (Gleissberg, 1944; Friis-Christensen, 1991), which was found using the solar cycle length as an indicator of solar activity. So in the end there may be a solar activity effect on the Earth's temperature (changing solar constant?) and this in turn may influence the height of the ionosphere.

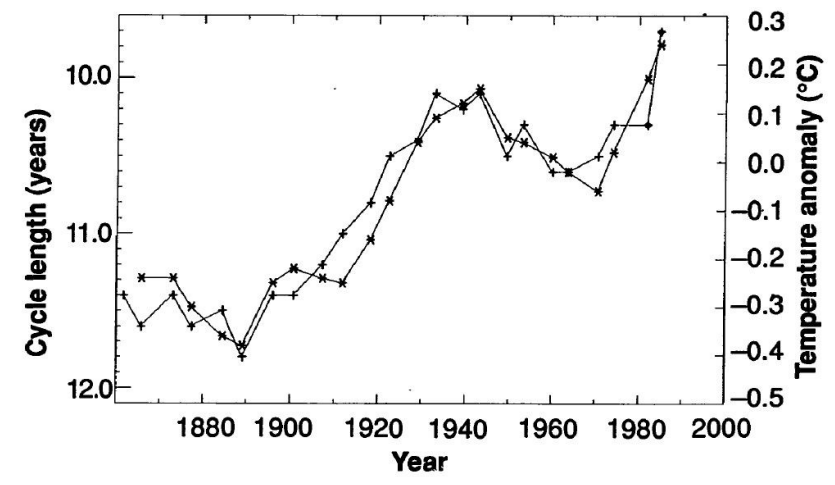

Fig. 5. Surface temperature (x) and solar cycle length (+) (after Friis-Christensen, 1991).

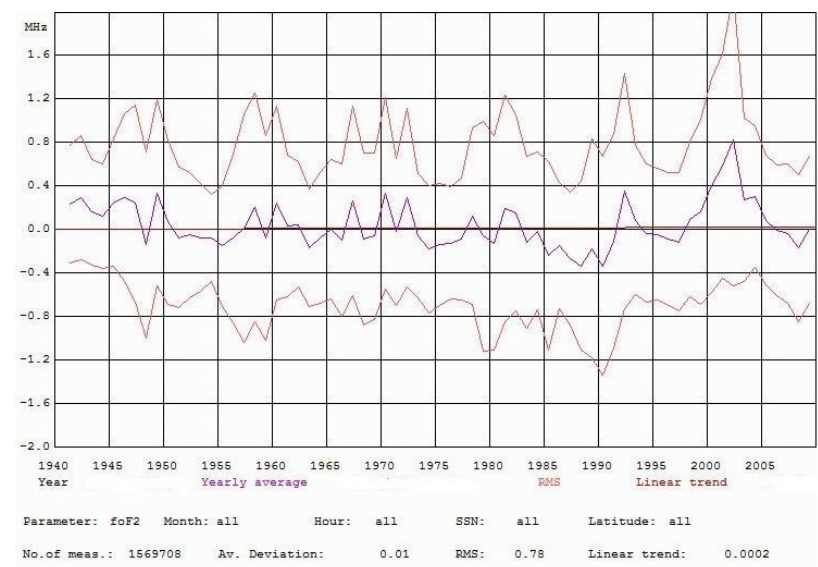

Fig. 6. Yearly average foF2(obs)-foF2(pred) from 1941 to 2009 and resulting trend line.

\section{Trend in the critical frequency foF 2}

In the new database there are 1569708 monthly hourly measured foF 2 values from more than 230 stations. Analogous to the height of the ionosphere, a comparison of the measurements with the values predicted for the critical frequency foF2 according to the CCIR method (ITU, 2010) was performed. There are about 20000 monthly values used for the calculation of each yearly average with substantially fewer values in the first 5 years. If one wishes to calculate a linear trend for foF2, this would be about $0.0002 \mathrm{MHz}$ year $^{-1}$ and this small value is totally insignificant, particularly taking into account the accuracy of the single measurements of only $0.1 \mathrm{MHz}$. Interestingly, none of the other effects observed in $\mathrm{hmF} 2$ can be seen in foF2. 


\section{Conclusions}

Particularly in the years of the long and low solar minimum 2005 to 2009 it becomes evident that the sunspot number does not sufficiently represent those parts of the solar spectrum which cause the ionisation and the height of the maximum ionisation. Rishbeth's theory of a lowering of the ionosphere by about 2 to $4 \mathrm{~km}$ in 40 years as a consequence of a $\mathrm{CO}_{2}$ increase by about $20 \%$ cannot be confirmed using ionospheric measurements on a global scale. Averaging the ionospheric observational data over the whole globe, may perhaps mask some local as well as time-dependent effects, which need further study. There seems to be a trend reversal in the height of the ionosphere in about 1963/1964, perhaps connected with a trend reversal in the Earth's surface temperature.

Acknowledgements. We acknowledge the effort of more than 230 ionospheric sounding stations who made their data available to the World Data Centres (WDC). Without these data the work reported here would not have been possible. The authors thank M. Rapp and J. Bremer for stimulating discussions and support. Advice and comments from two anonymous referees are highly appreciated. Topical Editor M. Förster thanks D. Bilitza and an anonymous reviewer for their help in evaluating this paper.

\section{References}

Bremer, J.: Ionospheric trends in mid-latitudes as a possible indicator of the atmospheric greenhouse effect, J. Atmos. Terr. Phys. 54, 1505-1511, 1992.

Bremer, J.: Trends in the ionospheric E and F regions over Europe, Ann. Geophys., 16, 986-996, doi:10.1007/s00585-998-0986-9, 1998.
Bremer, J., Damboldt, T., Mielich, J., and Süßmann, P.: Comparing long-term trends in the ionospheric F2-region with two different methods, J. Atmos. Solar-Terr. Phys., in print, doi:10.1016/j.jastp 2011.12.017 2012.

Damboldt, T. and Suessmann, P.: Consolidated Database of Worldwide Measured Monthly Medians of Ionospheric Characteristics foF2 and M(3000)F2, INAG Bulletin on the Web, INAG-73, www.ips.gov.au/IPSHosted/INAG/web-73/index.html, 2012.

Emmert, J. T., Lean, J. L., and Picone, J. M.: Record-low thermospheric density during the 2008 solar minimum, Geophys. Res. Lett., 37, L12102, doi:10.1029/2010GL043671, 2010.

Friis-Christensen, E. and Lassen, K.: Length of the Solar Cycle: An Indicator of Solar Activity Closely Associated with Climate, Science, New Series, 254, 5032, 698-700, (1 Nov 1991), 1991.

Gleissberg, W.: A table of secular variations of the solar cycle, Terrest. Magnet. Atmos. Electr., 243-244, 1944.

ITU: Recommendation ITU-R P.1239-2, International Telecommunication Union, Geneva, 2010

Jacobi, Ch., Hoffmann, P., Placke, M., and Stober, G.: Some anomalies of mesosphere/lower thermosphere parameters during the recent solar minimum, Adv. Radio Sci., 9, 343-348, doi:10.5194/ars-9-343-2011, 2011.

Lühr, H., Rother, M., Häusler, K., Fejer, B., and Alken, P.: Direct comparison of non-migrating tidal signatures in the electrojet, vertical plasma drift and equatorial ionization anomaly, J. Atmos. Solar-Terr. Phys., 75-76, 31-43, doi:10.1016/j.jastp.2011.07.009, 2012.

Rishbeth, H.: A greenhouse effect in the ionosphere?, Planet. Space Sci., 38, 945-948, 1990.

Rishbeth, H. and Roble, R. G.: Cooling of the upper atmosphere by enhanced greenhouse gases - Modelling of the thermospheric and ionospheric effects, Planet. Space Sci., 40, 1011-1026, 1992.

Solomon, S. C., Woods, T. N.,Didkovsky, L. V., Emmert J. T., and Quian, L.: Anomalously low solar extreme-ultraviolet irradiance and thermospheric density during solar minimum, Geophys. Res. Lett., 37, L16103, doi:10,1029/2010GL044468, 2010.

Shimazaki, T.: World wide daily variations in the height of the maximum electron density in the ionospheric F2 layer, J. Radio Res. Lab, 2, 85-97, 1955. 